\title{
Die rol van rituele en simbole in die identiteitsvorming van 'n geloofsgemeenskap - 'n Gereformeerde perspek- tief
}

H J C Pieterse

(Unisa)

\section{ABSTRACT}

The role of rituals and symbols in the identity of a faith community - a Reformed perspective

The political dispensation in South Africa since 1994 marginalised Afrikaansspeaking Dutch Reformed church members in the new South African society. Their identity is under pressure in a dominant culture that differs from their own. Anxiety and feelings of insecurity about their existence in the future are rife among many people in this church. In this context a new need for religious experiences of identity, belonging and safety opened up new experiments in the liturgy of the church. A new interest in rituals and symbols in the worship service came to the fore. This article discusses a Reformed perspective on the function and meaning of rituals and symbols in liturgy with a view to support the communicative discourse in seeking mutual understanding of the identity of their community of faith in a dominant, different culture.

\section{INLEIDING}

Die Afrikaanssprekende kerke van reformatoriese inslag verkeer sedert die politieke verandering in 1994 in 'n gemarginaliseerde posisie binne die breë samelewing. Die Afrikaanse gemeenskap se taal word stelselmatig uit die openbare lewe verwyder. Die openbare instellings soos Afrikaanstalige skole en universiteite kom onder al groter druk. Daar is 'n persepsie onder hierdie kultuurgroep dat hul nageslag geen kans het om posisies in die openbare lewe te beklee nie. Die geleenthede vir opwaartse mobiliteit in die samelewing sal waarskynlik in die toekoms afgesluit word. Die Afrikaanse kultuurgroep is ' $n$ minderheid in 'n dominante kultuurgroep waarvan hul kultuur en waardes verskil. Dit is 'n wesenlike gevaar dat latere generasies op die onderste kant van die samelewing kan beland'. Baie mense is besig om hul hoop op die toekoms te verloor.

Wanneer 'n minderheidskultuurgroep in 'n dominante kultuur hulself moet handhaaf, word die rol van godsdiens uiters belangrik. Vanuit 'n godsdienspsigologiese perspektief merk Jongsma-Tieleman op voetspoor 
van Erikson op dat godsdiens as dit goed is, die bewaker van die hoop is. "Godsdienst behoedt en bewaart de hoop op verschillende manieren. In de geloofsinhoud wordt de hoop gefundeerd in God, zodat menselijke levenswaarden op een existentieel niveau bevestigd worden. In godsdienstige vieringen wordt hieraan een rituele vorm gegeven, en wordt het hierdoor als het ware voelbaar gemaakt voor de gelovigen. En verder functioneert godsdienst als hoedster van de hoop doordat zij een maatschappelijk en cultureel instituut vormt" 2 . Hierdie insigte is vir kerk en teologie uiters belangrik in ons situasie. Dit laat die kollig val op de liturgie en op die kerk as geloofsgemeenskap. Dit het ook implikasies vir ons teologie.

Die implikasies vir die kerk as geloofsgemeenskap binne die Afrikaanse kulturele konteks het te make met die soeke en bevestiging van identiteit. Die soeke na gemeentelike identiteit in die nuwe situsie sal in die rigting van 'n kommunikatiewe identiteit moet wees. Hierin kan die denke van J Habermas ons lei. Die vind van 'n identiteit van 'n gemeente berus op 'n kommunikatiewe rasionaliteit waarin daar 'n diskoers op gang kom deur almal wat betrokke is, totdat onderlinge begrip en 'n mate van konsensus oor die waardes van die geloofsgemeenskap en hul identiteit in die nuwe situasie bereik word. Die onsekerheid oor identiteit in 'n veranderde situasie het ontstaan omdat daar 'n versteuring in die konsensus en kommunikasie van die groep gekom het ${ }^{3}$. Daarom moet die groep weer in 'n proses van kommunikatiewe handelinge diskoers voer totdat konsensus bereik word oor hul identiteit ${ }^{4}$. In ons situasie is daar nie meer konsensus oor die identiteit van die Afrikaanssprekende kerke van reformatoriese inslag in die nuwe situasie nie. Aan so 'n debat soos Habermas en De Roest voorstel, is daar 'n dringende noodsaak.

Jongsma-Tieleman stel dit duidelik dat die godsdiens en die liturgiese viering van 'n mindersheidskultuur binne 'n dominante (vreemde) kultuur wat hulself as marginaal of aan die onderpunt van die samelewing beleef, gedra moet word deur 'n kontekstuele teologie ${ }^{5}$. Voorbeelde hiervan is die (in Suid-Afrika nie meer bestaande) swart bevrydingsteologie en die feministiese teologie. Om in die liturgie die diepe gemeenskap met God te smaak wat die hoop en moed bou om in Suid-Afrika as kinders van die land binne ons eie kultuur te kan leef en werk, is 'n eie Afrikaanse kontekstuele teologie in die nuwe situasie nou nodig. Hierdie teologie moet ons identiteitsvorming van die gemeente en die liturgiese vorm en ervaring in die nuwe situasie dien. Dit is nou die tyd vir ons jong toegewyde teoloë om hul energie in hierdie rigting te ontplooi. Dit moet ' $n$ fatsoenlike teologie wees wat sy man in internasionale geselskap en in reformatoriese kring kan staan, maar dit moet 'n teologie wees wat uit ons konteks dink en vir die kerk in ons konteks koers gee. 
In hierdie artikel konsentreer ek egter op die liturgie as bewaker van die hoop en die uitdrukking van die identiteit van ons geloofsgemeenskap. Ek sal verder op die rol en betekenis van rituele en simbole konsentreer. Die rede daarvoor is voor die hand liggend. Oral in ons Afrikaanse kerke van reformatoriese inslag, word tans met die liturgie geëksperimenteer. Daar is 'n aanvoeling dat ons in die situasie van onsekerheid en moedeloosheid heil in die liturgie moet soek. Daar is egter baie verwarring onder ons in hierdie soeke na 'n eie identiteit en 'n deurleefde erediensviering. Die eksperimente in die rigting van die charismatiese styl lê ongelukkig die klem te swaar op die emosionele belewing. Verder word die ryke tradisie van ons gereformeerde erfenis onderskat. Daar is ook eksperimente met simbool en ritueel wat uit die tradisie van die kerk gaan put en dit op 'n vernuwende wyse weer aan die orde stel. Hierdie artikel wil die betekenis van simbole en rituele in ons liturgie vanuit 'n Gereformeerde perspektief aanspreek. Die doel is om hierdie saak (rituele en simbole) in die rigting wat Hoe lieflik is $u$ woning ${ }^{6}$ aandui, te bespreek.

\section{DIE UNIEKHEID VAN DIE CHRISTELIKE EREDIENS}

In die erediens is mense besig met iets heel anders as die gewone alledaagse besighede en handelinge. Daar heers ' $n$ unieke atmosfeer en daar vind 'n unieke gebeure plaas wat nêrens anders in die wêreld ervaar kan word nie. In die erediens vind daar 'n ontmoeting met God plaas. Dit is 'n lewende gesprek met God, en Christus is in die liturgiese gebeure lewend teenwoordig deur sy Gees en Woord.

Die wyse waarop die ontmoeting met God in die erediens plaasvind, geskied deur liturgiese handelinge (ritusse - op verbale en nie-verbale wyse) en simboliese taal. En dit alles word lewend en werklik gemaak deur die werk van die Heilige Gees. Al die bogaande uitsprake is tipies gereformeerde sieninge en stam op die teologiese insigte van Calvyn?

Die wesenlike kenmerk van die gereformeerde erediens is egter dat die liturgiese handelinge en die simboliese taal, die strukturering en vormgewing daarvan, op die Skrif gebou is. Deur die eeue en ook vandag probeer ons steeds die liturgie van die gereformeerde erediens Skriftuurlik verantwoord soos ons die Bybel verstaan aan die hand van ons geloofsbelydenisse, naamlik die Nederlandse Geloofsbelydenis, die Heidelbergse Kategismus en die Dordtse Leerreëls. Dit beteken egter nie dat ons teologiese verstaan en ons erediens-praktyk gestol het, en nie meer dinamies in elke nuwe situasie lewend en sinvol kan geskied nie. Die opdrag vir die Gereformeerde teologie bly steeds om in elke geslag en nuwe situasie 
steeds te reformeer op grond van die bevrydende waarheid van die Woord van God ${ }^{8}$. In my eie werk het ek probeer om hierdie opdrag uit te voer deur steeds nuwe wêrelde in die praktiese teologie te verken en in die nuwe situasie te vra na die sin van ons geloof soos ons dit in ons tradisie verstaan 9 .

In die lig van hierdie Skriftuurlike uitgangspunt sal ek fokus op 'n beskrywing van rituele en simbole in 'n Gereformeerde erediens.

\section{DIE RITUELE (LITURGIESE HANDELINGE)}

Die liturgiese handelinge wat in die Gereformeerde erediens geskied, is gebou op die Skrif. Die ordes van die diens funksioneer binne die raam van die Skrif en ons geloofsbelydenisse, en is gestruktureer soos dit neerslag gevind het in die geskiedenis van die Gereformeerde kerke en ons kultuur oor die afgelope vier eeue sedert die Reformasie ${ }^{10}$. 'n Mens kry natuurlik nie 'n voorgeskrewe liturgie pasklaar in die Bybel nie. Daar is egter verskillende elemente wat in die Skrif vermeld word, soos Skriflesing (1 Tim 4:13; 1 Tess 5:27); die sing van psalms en gesange (Ef 5:19; Kol 3:16); gebede (Hand 2:42; 1 Tim 2:1-2); die "amen" as respons op die gebed (1 Kor 14:16); die preek (1 Kor 14:26; Hand 20:7); 'n vorm van belydenisaflegging (1 Tim 6: 12); die offergawes (1 Kor 16:2; 2 Kor 9:1013); die groet (Rom 1:7; 1 Kor 1:3); die heilige kus (Rom 16:16; 1 Kor 16:20); en die seënbede (2 Kor 13:13) ${ }^{11}$.

Die vormgewing en die orde van die verskillende liturgiese handelinge soos ons dit hierbo aangegee het (wat afgelei is uit die Skrif) het vorm gekry deur die geskiedenis van die liturgie sedert die Reformasie. Hierdie vorm het op 'n merkwaardige wyse sy wesenlike struktuur deur die eeue behou. Die rede is weer eens die feit dat dit op die Skrif gebou is. Die hart van die evangelie klop in hierdie orde. Die orde verloop volgens 'n mens se gang in die vind van heil: God se inisiatief na die mens toe met sy genade; die berou van die mens oor sy sonde en die belydenis daarvan; die vryspraak van die evangelie wat volg op die berou; die belydenis van ons geloof; die aktuele Woord van God in die verkondiging; die dankbaarheid van die gemeente in gebed, sang en offergawe. Hierdie boodskap en belewing van die evangeliese heil word telkens weer in die liturgiese handelinge reëel deur die gemeente in die lewende teenwoordigheid van die Heer uitgespeel.

Die liturgiese handelinge in die erediens geskied as dialoog in 'n lewende gesprek, gebou op die Skrif, tussen God en mens. Die kommunikasie tussen God en mens is in die Skrif as 'n lewende gesprek geopen- 
baar. Die selfbekendstellingswoorde en dade van God in die Ou Testament het telkens in gesprek met mense plaasgevind. God se optrede by die roeping van Moses kan gesien word as "a consistent characteristic of the selfdisclosures of God: revelation is dialogical"12. God se handelinge met die mens was nooit eensydig nie. Hy het die mens as gespreksgenoot en bondgenoot opgeneem in sy beweging in die geskiedenis.

Die optrede van Jesus, waarin hy God se wil aan ons kom bekend maak het, was by uitstek dialogies. Hy het 'n dialogiese styl gehad waarin hy vrae en diskussie verwelkom het. Sy handelinge met mense was meer uitnodigend as met dwang. Heyns ${ }^{13}$ werk met 'n dialogiese inspirasieteorie van die Skrif. Omdat die aard van God se openbaring en ontmoeting met die mens in die Skrif in die vorm van 'n gesprek plaasgevind het, geskied die erediens as 'n gesprek en het die prediking 'n dialogiese aard. Dit is die rede waarom ons kommunikasieteorie vir die prediking en die erediens dialogies moet wees ${ }^{14}$.

Die liturgiese handelinge in die erediens van die Ned Geref Kerk is as 'n gesprek tussen God en die gemeente georden wat so verloop dat die gang van die evangeliese heil in die gesprek ontvou. Die rubrieke in hierdie orde, vanaf die votum tot by die seën, is deeglik in ons boek oor die liturgie behandel ${ }^{15}$.

\section{SIMBOLE}

Ricoeur ${ }^{16}$ se simboolteorie maak interessante insigte oop oor die funksie en waarde van simbole, ook Christelike simbole. Deur die simbool ontvang 'n mens betekenis vanuit 'n diepe, voortalige oer-werklikheid. Hierdie werklikheid bestaan uit 'n groot aantal sinslae. Die krag van simbole is daarin geleë dat dit gewortel is in 'n werklikheid wat buite die mens se taal val, soos die Heilige, die kosmos, ensovoorts. Die kommunikasiekrag van simbole lê daarin opgesluit dat dit na die wêrelde verwys wat buite ons sigbare werklikheid bestaan. Simbole fuksioneer as vensters wat ons 'n uitsig gee op die onuitspreeklike, die oneindige en die transendente ${ }^{17}$.

Simbole moet deur taal tot uitdrukking kom. In 'n simbool sit twee wêrelde: die nie-talige en die talige (linguistiese). Die toegang tot die simbool is sy primêre, nie-talige betekenis, wat deur nadenke (simbole laat ons dink, sê Ricoeur) en deur 'n simbool-semantiek te konstrueer, verkry kan word. In die simbool word toegang verkry tot die werklikheid van kragte en magte wat groter is as wat ons in taal kan vasvat. Maar deur die dialektiek tussen metafore en simbole kan die simbool in taal uitgedruk word. Metafore is deel van 'n netwerk waar die een die ander oproep - 
soos byvoorbeeld die metafore oor die koninkryk van God in die gelykenisse van Jesus. Hierdie netwerke van metafore bring hulle nader aan die simbool. Basis- of grondmetafore soos "smet" vir die kwaad en "rein gewas" vir die heil vorm 'n brugfunksie om simbole, byvoorbeeld van kwaad of heil (soos byvoorbeeld die kruis) ter sprake te bring18. Die simbool laat sy oorvloed van betekenis vry uit die ervaringe wat dit oproep deur sy letterlike interpretasie heen wanneer dit in taal uitgespreek word. So byvoorbeeld dui ons Christelike simbole op die versoening in Christus: die kruis, die Christus monogram, die duif, die vis met die ichthus-inskripsie, brood, water en wyn. Hierdie simbole is almal Bybels gefundeerd en het vorm gekry in ons kultuur ${ }^{19}$.

Hierdie simbole word egter in ons godsdienstige taal verwoord om die grondverhaal van die heil van God vir ons in die evangelie as verlossing uit die kwaad uit te druk: in die prediking, in die ritme van die kerkjaar, in die sakramente, in die kerkmusiek en -sang. Simbole funksioneer in die Christelike taal in begrippe soos kwaad, smet, skuld en versoening. Die verbinding van die ervaring van die kwaad (die belewing van sonde as gevolg van die kwaad) en die ervaring van die verlossing daarvan deur die versoening in Christus, word uitgedruk in simboliese sin in die volgende kategorieë: versoening "ondanks" die kwaad; versoening met die Heilige (God) danksy die verlossingsdaad deur Christus waartoe ons nie in staat is nie; en die oorvloed van genade ("die hoeveel te meer") danksy die versoening deur Christus ${ }^{20}$.

Materiële simbole soos die kruis, die duif, ensovoorts, en simbole wat tot taal gebring word en in die Gereformeerde teologie en praktyk funksioneer, soos "sonde", "skuld" (die kwaad) en die verlossing daarvan, soos "versoening", is ook op Gereformeerde teologiese styl op die Skrif gebou. Die gebruik daarvan in die erediens vertoon ook telkens 'n evangeliese struktuur soos ons dit in die openbaring in die Skrif aflees. Die simbole vertel die verhaal van ons sonde en die verlossing daarvan deur die heilsdade van Christus - dink maar aan die brood en wyn van die Nagmaal, en die water van die doop met die verdere simbole van die tafel en die doopfont in die liturgiese ruimte.

\section{KONKLUSIE}

Die liturgiese handelinge en die funksionering van simbole in die Gereformeerde erediens het hierdie één uitstaande kenmerk, naamlik dat dit op die Skrif gebou is, soos ons die Skrif in ons tradisie verstaan. Dit is verder so gestruktureer en georden dat dit die heil van die evangelie in Christus 
bemiddel, dit kommunikeer. Dit is die groot doel daarvan. En in die totale liggaamlike ervaring in die gereformeerde erediens deur die liturgiese handelinge en die simboliese taal heen, word die geestelike ontmoeting met God gesmaak deur Woord en Gees ${ }^{21}$. Want ons glo onwrikbaar op grond van die beloftes van God in die Skrif dat as ons die Godswoord deur die Skrifwoorde heen bedien, en die Skriftuurlike gang van die evangelie deur ons hele erediensinrigting en -handelinge kommunikeer, die Heilige Gees dit alles lewend en werklik maak.

Deur op sinvolle wyse binne ons tradisie op 'n vernuwende wyse ons liturgie ten opsigte rituele en simbole in te rig kan die liturgiese viering 'n bydrae lewer tot die bepaling van ons identiteit en so die hoop bewaar.

\section{NOTAS:}

1 P E Jongsma-Tieleman, Godsdiens als speelruimte voor verbeelding, Kampen $1996,116$.

2 Jongsma-Tieleman, $a w, 109$.

$3 \mathrm{H}$ de Roest, Communicative Identity. Habermas' perspectives of discours as a support for practical theology, Kampen 1998, $223 \mathrm{ff}$.

4 J Habermas, Theorie des kommunikativen Handelns (Bd 1 \& 2), Frankfurt am Main, 1982.

$5 \quad$ Jongsma-Tieleman, $a w, 117$.

6 C J A Vos \& H J C Pieterse, Hoe lieflik is u moning, Pretoria 1997.

7 T Brienen, De liturgie bij Johannes Calvijn, Kampen 1987.

8 W D Jonker, Bevrydende waarheid. Die karakter van die gereformeerde belydenis, Wellington 1994.

9 H J C Pieterse, Verwoording en prediking, Pretoria 1985 (Engelse uitgawe: Communicative Preaching, Pretoria 1987, $21991,{ }^{3} 1995$.

10 Vergelyk A C Barnard, Die Erediens, Pretoria 1981.

11 Algemene Kommissie vir die Erediens van die Ned Geref Kerk, Die erediens. 'n Handleiding by die kerkboek, Kaapstad 1976, 8.

12 G W Swank, Dialogic Style in Preaching, Valley Forge 1981, 28.

13 J A Heyns, Dogmatiek, Pretoria 1978, 21.

14 H J C Pieterse, Gemeente en prediking, Halfway House 1991, 7-20; Vos \& Pieterse, $a w, 19-27$.

15 Vos \& Pieterse, $a w, 200-255$.

16 P Ricoeur, Interpretation Theory. Discourse and the Surplus of Meaning, Fort Worth, Texas 1976, 53-69.

17 G Otto, Predigt als Sprache, Theologia Practica 17, $1 / 2$ (1982) 117-127, 125; M Karecki, Formation for Mission, Pretoria 1995.

18 Ricoeur, $a w, 60-66$.

19 Vos \& Pieterse, $a w, 124$.

20 P Ricoeur, Kwaad en bevrijding. Filosofie en theologie van de hoop, Rotterdam $1971,310$.

21 Vos \& Pieterse, $a w, 107-130$. 